\title{
Construction and Composition of the Squid Pen from Doryteuthis pealeii
}

\author{
MARK A. MESSERLI ${ }^{1, *}$, M. JAHIR RAIHAN ${ }^{1}$, BRIAN M. KOBYLKEVICH $^{1}$, AUSTIN C. BENSON $^{1}$, \\ KRISTI S. BRUENING ${ }^{1}$, MICHAEL SHRIBAK ${ }^{2}$, JOSHUA J.C. ROSENTHAL ${ }^{2}$, AND JOEL J. SOHN ${ }^{3}$ \\ ${ }^{1}$ Department of Biology and Microbiology, South Dakota State University, Brookings, South Dakota 57007; ${ }^{2}$ Eugene Bell \\ Center for Regenerative Biology and Tissue Engineering, Marine Biological Laboratory, Woods Hole, Massachusetts 02543; \\ and ${ }^{3}$ Department of Molecular and Cellular Biology, Harvard University, Cambridge, Massachusetts 02138
}

\begin{abstract}
The pen, or gladius, of the squid is an internalized shell. It serves as a site of attachment for important muscle groups and as a protective barrier for the visceral organs. The pen's durability and flexibility are derived from its unique composition of chitin and protein. We report the characterization of the structure, development, and composition of pens from Doryteuthis pealeii. The nanofibrils of the polysaccharide $\beta$ chitin are arranged in an aligned configuration in only specific regions of the pen. Chitin is secreted early in development, enabling us to characterize the changes in pen morphology prior to hatching. The chitin and proteins are assembled in the shell sac surrounded by fluid that has a significantly different ionic composition from squid plasma. Two groups of proteins are associated with the pen: those on its surface and those embedded within the pen. Only 20 proteins are identified as embedded within the pen. Embedded proteins are classified into six groups, including chitin associated, protease, protease inhibitors, intracellular, extracellular matrix, and those that are unknown. The pen proteins share many conserved domains with proteins from other chitinous structures. We conclude that the pen is one of the least complex, load-bearing, chitin-rich struc-
\end{abstract}

Received 14 August 2018; Accepted 30 April 2019; Published online 8 July 2019

* To whom correspondence should be addressed. Email: mark.messerli@ sdstate.edu.

Abbreviations: ADAMTS, a disintegrin and metalloproteinase with thrombospondin motifs; BPTI, bovine pancreatic trypsin inhibitor; CBD, chitinbinding domain; CBD2, chitin-binding type 2 domain; DI, deionized; FACT, facilitates chromatin transactions; M1, 2, methods 1, 2; MS/MS, tandem mass spectrometry; PBS, phosphate-buffered saline; PCR, polymerase chain reaction; PP, predicted protein; RACE, rapid amplification of cDNA ends; RTA, Real-Time Analysis; SDS-PAGE, sodium dodecyl sulfate polyacrylamide gel electrophoresis.

Online enhancements: supplemental tables. tures currently known and is amenable to further studies to elucidate natural construction mechanisms using chitin and protein.

\section{Introduction}

The pen of the squid is considered an internalized shell, homologous to the heavily mineralized external shells of other molluscs (Naef, 1928; Young et al., 1998). Pens are most commonly transparent, tough, flexible, non-mineralized skeletal elements composed of chitin and proteins. Along its dorsal surface, the pen supports the mantle muscles, whose expansion and contraction produce the jet propulsion of squid locomotion (Williams, 1909; Gosline and DeMont, 1985; Thompson et al., 2014), powerful enough to launch squid into flight (O'Dor, 2013). On the ventral surface of the pen, muscles are attached that control the siphon and give direction to the jet, control the rotational motion of the head and its retraction into the mantle cavity, and support the musculature of digestive organs (Williams, 1909; Young et al., 1998; Thompson et al., 2016). However, some squid, such as the bobtail squid, that live a benthic existence form no pen (Cole and Hall, 2009; Lee et al., 2009); and others, such as the bigfin reef squid, have a pen with some degree of mineralization (Subhapradha et al., 2013).

The pen is valuable as a source of information about the life history of the squid and also as a marine resource of commerce. The pen enlarges over the life cycle of the squid, incorporating stable environmental isotopes and providing a record of an individual's age and also its feeding and migratory behavior (Bizikov, 1995; Ruiz-Cooley et al., 2010; Lorrain et al., 2011; Merten et al., 2017). In addition, the pen is a rich source of $\beta$-chitin, which has many commercial applications (Vournakis et al., 2003; Di Martino et al., 2005; Ma et al., 2011; Fernandez and Ingber, 2014; Das et al., 2015); and many efforts report characterization of the purified chitin (Chaussard and 
Domard, 2004; Lavall et al., 2007; Cortizo et al., 2008; Ianiro et al., 2014; Cuong et al., 2016). However, pen construction and its protein composition have largely been ignored.

In other organisms where external shells are constructed with chitin-protein composites, shells can be heavily mineralized, as in decapods, gastropods, and bivalves (Raabe et al., 2005; Marin et al., 2008; Fernandez and Ingber, 2013; Suzuki and Nagasawa, 2013). Recent studies have attempted to characterize the proteins associated with chitin by using transcriptomic and proteomic approaches (Marin et al., 2013). Many of the recovered proteins are unknown; and for many others it is difficult to decide whether a particular protein is involved in the assembly, organization, and nucleation of the inorganic matrix, whether it is involved in the structure and biosynthesis of the chitin-protein matrix, or both (Marin et al., 2008). Furthermore, many other chitin-protein composites are sclerotized, having been hardened through dehydration and covalent crosslinking of structural macromolecules, including insect cuticles and wings and cephalopod beaks (Andersen, 2010; Fernandez and Ingber, 2013; Tan et al., 2015). Extraction and identification of the cross-linked proteins are very challenging (Fernandez and Ingber, 2013; Tan et al., 2015). In order to learn how chitin and proteins are assembled into three-dimensional structures, it would be ideal to study a chitin-protein composite without mineralization or sclerotization in a model organism that can be studied at the cellular and molecular level from its embryonic origin to adulthood. The pen of Doryteuthis pealeii is one such example.

The squid pen is constructed by, and contained within, the closed shell sac, an epithelium that completely surrounds the pen (Williams, 1909; Hopkins and Boletzky, 1994). In the squid Loligo vulgaris, it was suggested that the ventral shell sac epithelium is primarily responsible for secretion of the materials that make up the pen, and that the dorsal epithelium plays a more significant role in anchoring the pen to the mantle musculature (Hopkins and Boletzky, 1994). These conclusions are based on differences in cellular morphology and organelle quantity between the ventral and dorsal regions of the shell sac rather than direct evidence of the secretion of the pen constituents (Hopkins and Boletzky, 1994). In fact, much of the evidence regarding the secretion and organization of chitin and proteins in the pen is based on various imaging methods and analogies to known structures rather than on the identification of individual proteins and how they interact with other proteins and/or chitin (Hunt and Nixon, 1981; Hunt and El Sherief, 1990; Wu et al., 2003; Yang et al., 2014; Cuong et al., 2016).

Pens from various species of squid contain, by weight, $25 \%-$ $49 \%$ chitin and $43 \%-75 \%$ protein, with very low ash (inorganic composition) after thermo-gravimetric analysis (Hunt and Nixon, 1981; Wu et al., 2003; Chaussard and Domard, 2004; Lavall et al., 2007; Cortizo et al., 2008; Cuong et al., 2016). In the small samples of the pen that were studied, chitin nanofibrils appeared wrapped in a protein layer (Raabe et al., 2005; Yang et al., 2014; Merzendorfer et al., 2016), and $\alpha$-helical protein coils and $\beta$-chitin nanofibrils were aligned parallel to the long axis of the pen (Yang et al., 2014). While an unidentified collagen has been inferred to surround pens of Illex argentinus (Wu et al., 2003), no other proteins associated with the pen have been identified. Amino acid analysis has been performed and indicates that pen proteins from three different species are enriched with hydrophobic amino acids (Hackman, 1960; Hunt and Nixon, 1981; Wu et al., 2003; Cuong et al., 2016).

The identity of the pen proteins and the mechanisms by which they assemble with the chitin nanofibrils to construct and repair this complex three-dimensional structure remain unknown. Here we use microscopy to describe the chitinprotein organization in whole adult pens and the developmental morphology of embryonic pens. We determine the inorganic composition of the extracellular fluid surrounding the pen to begin to understand how the pen remains without mineralization. We also report and discuss the proteins that are associated with adult pens and compare them to the proteins associated with other chitinous structures.

\section{Materials and Methods}

\section{Collection and preparation of biological materials}

Pens were removed from the shell sacs of freshly sacrificed adult squid (Doryteuthis pealeii (Lesueur, 1821)). An incision in the mantle was made along the midline, and the pen was removed by peeling back the mantle and gently pulling on the pen. Two methods were used for removing adhering tissue. Method 1 (M1) involved removing all visible soft tissue by rubbing pens with gloved hands under deionized (DI) water. Method 2 (M2) involved rinsing pens with isotonic saline while scrubbing the pen surface with a small plastic bristled brush. Dehydration of whole pens was performed in a short period of time by using a vacuum evaporator. Pulverized pens were chopped into a fine powder with a blade grinder (Capresso, Closter, NJ).

Embryonic squid and hatchlings were collected from squid egg capsules that were deposited in the squid holding tanks of the Marine Resource Center (Marine Biological Laboratory, Woods Hole, MA) between June and September and held at ambient temperature. Embryos were staged according to Arnold (1965).

Shrimp shells appear similar to squid pens with regard to low covalent cross-linking and low mineralization. Therefore, they were used to compare protein extraction and general composition with the squid pen, despite the fact that shrimp shells contain $\alpha$-chitin rather than the $\beta$-chitin in the squid pen. The shells were obtained from chilled white shrimp (Litopenaeus setiferus). We used M2 to remove cellular material from the shrimp shells after the shells were peeled away from the body. Shells were dried and pulverized as described above.

\section{Microscopy}

We examined pen construction by using polarized light, fluorescence, and electron microscopy. Images of dried pens (M1) were obtained with transmitted light that was unpolarized 
or polarized to aid in identification of chitin-protein alignment in whole pens. Four individual images were assembled to make each composite image. The squid pen was placed between crossed polarizer and analyzer filters during illumination with polarized light. Filters were mounted on a Zeiss (Jena, Germany) Discovery v12 microscope equipped with a color digital camera. Polarizers were rotated to achieve the maximum extinction (dark in the absence of anisotropic material). Isotropic materials remained dark when rotated between polarizers. Anisotropic materials became brighter at set intervals when rotated between polarizers. In order to obtain the maximal (brightest) birefringence signal, the long axis of the pen was oriented at $45^{\circ}$ to the transmission axis of the polarizer. The anisotropic structures in the pen produced Newton interference colors. The hue corresponded to the magnitude of birefringence retardation and could be estimated by the MichelLévy color chart (Oldenbourg and Shribak, 2010).

Fluorescence microscopy of pen development was performed by staining pen chitin with Calcofluor white (SigmaAldrich, St. Louis, MO) at a final concentration of $0.01 \%$. Specimens were fixed in phosphate-buffered saline (PBS) with $2 \%$ paraformaldehyde and rinsed with $0.1 \%$ Triton $X-100$ in PBS to remove membranes. Samples were rinsed in PBS before staining with Calcofluor white for one hour and were destained for one hour with multiple exchanges of PBS. Images were collected using a Zeiss two-photon LSM platform configured on an inverted Observer Z1 microscope. Embryos and hatchlings were positioned dorsal side down in PBS, and zstacks of images were collected of the curved pen. Calcofluor was excited with a Coherent (Santa Clara, CA) Chameleon II laser at $705 \mathrm{~nm}$, and the emitted light was collected with an internal detector at 420-492 nm. Rhodamine phalloidin (ThermoFisher Scientific, Waltham, MA) was used to stain mantle actin, using 540-nm excitation and 565-nm emission in order to determine the association between the pen and the mantle. Stacks of images were projected onto a single plane using the Zprojection function in ImageJ software (Rasband, 1997-2018).

To identify finer detail on the surface of dehydrated pens, we used scanning electron microscopy (SEM) with a Zeiss SUPRA 40vp Gemini scanning electron microscope. Pens were attached to an aluminum specimen mount (Ted Pella, Redding, CA) using double-sided carbon tabs (Ted Pella) and sputtercoated with a 6-nm layer of platinum, using a Leica (Wetzlar, Germany) EM MED020 high vacuum coating system. Images were captured with Zeiss SMARTSEM software. Dorsal and ventral surfaces of the squid pens were investigated.

\section{Shell sac ion composition}

The ionic composition of the extracellular fluid surrounding the pen was determined in order to understand the chemical environment in which the pen is constructed. Extracellular fluid was diluted 100-fold, and the free ionic concentration was determined, taking into account the dilution. Water content from freshly isolated pens was determined by weighing the hy- drated pens in $15-\mathrm{mL}$ conical tubes before and after vacuum evaporation of the water in each pen. DI water equal to 100 times the original water content was added back to each tube to rehydrate each pen and dilute the ionic composition before analyzing the solute levels. Ion chromatography and colorimetric assays were performed at the Water Resources Research Center at the University of New Hampshire (Durham). We report the mean \pm standard deviation of the free ion concentration for five whole pens.

\section{Shell sac transcriptome}

A shell sac transcriptome of $D$. pealeii was prepared by excising both medial and lateral sections $\left(25 \mathrm{~mm}^{2}\right)$ of the ventral shell sac from freshly isolated and dissected adult squid. Total RNA was extracted from the tissue by using the RNAqueous kit (ThermoFisher Scientific) and was converted into libraries by using polyA selection with the Illumina (San Diego, CA) TruSeq Stranded mRNA Library Preparation Kit LT. Libraries were pooled prior to sequencing. Samples were sequenced by using an Illumina HiSeq 2000 flow cell with TrueSeq SBS version 3 reagents (Illumina). Illumina sequencing was performed using $2 \times 150 \mathrm{bp}$ paired-end sequencing cycles. Base calling was performed with Illumina Real Time Analysis (RTA) version 1.17.21.3, and output of RTA was demultiplexed and converted to FastQ with Illumina Bcl2fastq version 1.8.4. Sequencing data from all samples were pooled for assembly. Data went through two stages of read trimming: quality-based trimming using Trimmomatic version 0.33 (Bolger et al., 2014), followed by k-mer spectral analysis to remove low-abundance k-mers, using the khmer 2.0 package (Crusoe et al., 2015). FastQC version 0.11.3 (Andrews, 2010) was used to check data quality before and after trimming. After filtering, highquality fragments were used for de novo transcriptome assembly by using Trinity version 6.0.2 (Hass et al., 2013). SeqClean (Gene Index Project, 2006) was used to trim polyA tails and remove low-complexity sequences. For functional annotation, assembled transcripts were blasted against the Swiss-Prot database, and best hits with $P$-values less than $10^{-3}$ were selected. All sequencing reads were deposited into the National Center for Biotechnology Information (NCBI) small-reads archive under the following accession numbers: SRX817965 for the marginal (lateral) epithelial layer and SRX817964 for the ventral (medial) epithelial layer.

\section{Rapid amplification of cDNA ends}

In order to obtain more complete sequence information for the protein with greatest relative abundance, we used rapid amplification of cDNA ends (RACE). Total RNA was extracted from the tissue of the lateral, ventral shell sac by using RNeasy (Qiagen, Hilden, Germany). cDNA with $5^{\prime}$ and $3^{\prime}$ adapter regions was made using the FirstChoice RLM-RACE kit (ThermoFisher Scientific). RACE was achieved using $3^{\prime}$ and $5^{\prime}$ RACE 
primers provided with the kit and internal primers for the sequence listed below.

Forward

GTGCCCCTGGTACTCTCTATT

CCTGAAGAACCCGCCAAAT

GCCCCAGGAACCGCTTATT

\section{Reverse \\ ATGTGGGCAACAACAGGTTTAT CGGCTGATACACAAACCTTTT}

Polymerase chain reaction (PCR) was performed with LongAmp Taq 2X Master Mix (New England Biolabs [NEB], Ipswich, MA). Nested priming was performed to reduce nonspecific amplification prior to sequencing. Gel extraction and DNA purification with Monarch DNA gel extraction (NEB) and Monarch PCR and DNA Cleanup Kit (NEB) were used, when necessary, to clean up PCR products prior to sequencing by GenScript (Piscataway, NJ).

\section{Pen protein extraction and identification}

We determined the relative protein content of the pens by comparing the dry weight of whole and pulverized pens before and after treatment with $1 \mathrm{~N} \mathrm{NaOH}$ to hydrolyze the proteins and minimize deacetylation of chitin (Chaussard and Domard, 2004; Ianiro et al., 2014). Pulverized pens (0.25 g) were dissolved in $40 \mathrm{~mL}$ of $1 \mathrm{~N} \mathrm{NaOH}$ and incubated overnight at either room temperature or $95^{\circ} \mathrm{C}$. The next day, the material was rinsed with $\mathrm{NaOH}$ to remove the amino acids before rinsing with $\mathrm{DI}$ water to remove the $\mathrm{NaOH}$. The wet material was vacuum dried and reweighed. We report the mean percent weight \pm standard deviation.

Whole proteins were removed from pulverized pens with treatments of either $8 \mathrm{~mol} \mathrm{~L}^{-1}$ guanidine $\mathrm{HCl}$ or $8 \mathrm{~mol} \mathrm{~L}^{-1}$ urea with $5 \%$ acetic acid. Pulverized pens $(0.25-0.5 \mathrm{~g})$ were incubated in 2 exchanges of $10 \mathrm{~mL}$ of extraction buffer for 30 minutes each with gentle agitation. We pelleted the chitin with centrifugation and precipitated proteins from the supernatant, using $90 \%$ ethanol (guanidine) or $80 \%$ acetone (urea). Proteins were resuspended in loading buffer for separation by using sodium dodecyl sulfate polyacrylamide gel electrophoresis (SDS-PAGE). The lane was cut into fragments to contain all proteins and was prepared for shipment according to the instructions provided by the Mass Spectrometry and Proteomics Resource Laboratory (Harvard University, Cambridge, MA). Protein fragments were made using in-gel digestion with trypsin, separated using high-performance liquid chromatography, and identified with the help of tandem mass spectrometry (MS/ MS). The spectral data of the peptides were correlated with sequences from the squid transcriptome to identify pen transcripts, using the Proteome Discoverer search engine (ThermoFisher Scientific). All data were filtered to $1 \%$ false discovery rate. BLAST was used in UniProt and NCBI to identify homologous proteins and identify gene ontology terms, conserved domains, and protein similarity. The procedure above would not extract proteins that were covalently bound to chitin and that were present in other chitinous structures (Andersen, 2010; Tan et al., 2015).

We attempted to remove covalently bound pen proteins by using chitin oxidation (Vold and Christensen, 2005) and also selective protein hydrolysis (Tan et al., 2015). Prior to extraction of covalently bound proteins, noncovalently bound proteins were removed by rinsing 8 times with $8 \mathrm{~mol} \mathrm{~L}^{-1}$ guanidine followed by 8 rinses with acetate buffer. This method removed noncovalently bound proteins as assessed by the loss of a protein pellet after the precipitation step. We attempted to remove covalent proteins from chitin by using chitin oxidation with $10 \mathrm{mmol} \mathrm{L}^{-1}$ periodate (Sigma-Aldrich) in $100 \mathrm{mmol} \mathrm{L}^{-1}$ acetate buffer ( $\mathrm{pH} 4.5)$ for 30 minutes at room temperature with gentle agitation. A fraction of the pen chitin was deacetylated, and periodate exposure hydrolyzed the deacetylated chitin (Vold and Christensen, 2005). This periodate treatment was gentle on proteins (Woodward et al., 1985). Periodate-liberated proteins were precipitated in acetone, separated with SDS-PAGE, excised, and identified. We also attempted to remove covalently bound proteins by using hydroxylamine treatment because it was previously successful in releasing some proteins from the squid beak (Tan et al., 2015). Noncovalently bound proteins were removed from pulverized pen as described above, and remaining material was treated with hydroxylamine, using the procedure described by Tan et al. (2015). Proteins were precipitated and identified.

\section{Results}

\section{Pen structure and development}

A whole pen from an adult Doryteuthis pealeii was illuminated with transmitted unpolarized light (Fig. 1A) and transmitted polarized light (Fig. 1B). The illustration of the adult squid in Figure 1 shows the location and orientation of the pen (shown in black). The pen is bilaterally symmetric, with a thick, narrow anterior region and a broad, thin posterior region known as the vane. The rachis, or spine, runs the length of the pen but is thicker toward the anterior. Illumination with polarized light results in bright colors (Fig. 1B). This indicates that the microstructure of the pen is highly birefringent, having two refractive indices, depending on the orientation of the polarization plane. When the polarizer and analyzer are removed, the pen is transparent (Fig. 1A), indicating that there is no pigmentation and no restriction of light by minerals and that the color is created by birefringence only. The greatest birefringence appears in the rachis, the anterior region of the pen, and the lateral edges of the vane. The lack of color in the body of the vane indicates that there is much less birefringence. The rachis and narrow anterior region of the pen have the greatest 


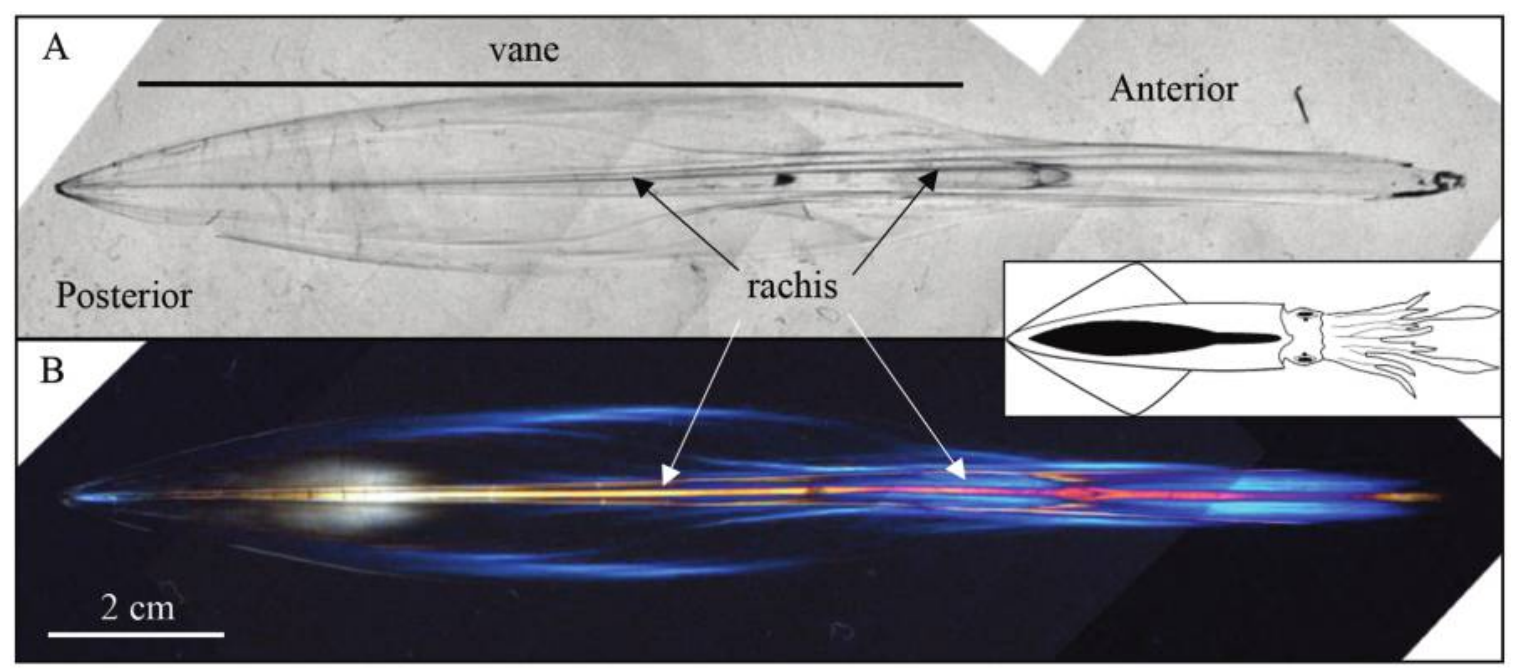

Figure 1. Transmitted light images of an adult squid pen. (A) Unpolarized, transmitted light illumination of a dried pen reveals a transparent combination of chitin and protein. (B) Polarized light illumination of the pen reveals a great degree of birefringence (colored regions) along the long axis of the pen. The inset shows an illustration of an adult Doryteuthis pealeii from the dorsal view with the same orientation and with its pen colored black.

alignment of macromolecules; however, the body of the vane is less uniform in chitin-protein alignment.

The pen is secreted in layers, visualized with SEM. Removal of a small superficial layer of the pen exposes multiple layers beneath and in close proximity (white arrows in Fig. 2A). The shell sac epithelium (white triangles in Fig. 2B) adheres tightly to the dorsal surface of the pen even after attempts to remove it from the pen with $\mathrm{M} 2$.

The birefringence of the adult pen encouraged us to follow development of the embryonic pen in vivo with polarized light. However, the birefringence of the overlying mantle skeletal muscle overwhelmed the birefringence of the chitin and protein in the pen (not shown). Instead, we characterized pen development by using the fluorescent chitin stain Calcofluor white. Calcofluor selectively stains the squid pen, with weak staining of surrounding tissues (Fig. 3A-E). While emybronic development of the mantle begins at stage 19 (Arnold, 1965, 1990), we observed the first sign of chitin secretion beneath the mantle at stage 23 (Fig. 3A). Development of the narrow, anterior pen appears first (Fig. 3A). However, further elongation occurs simultaneously with elaboration of the lateral edges of the vane. First, an inverted V forms at stages 25-26 (Fig. 3B) along the anterior-posterior axis; later, an inverted $\mathrm{Y}$ forms at stage 27 (Fig. 3C) as the anterior region elongates more rapidly than the posterior. Continued elaboration at stage 28 (Fig. 3D) is associated with elongation of both the narrow, anterior pen and the lateral edges of the wider, posterior vane. The central, posterior-most segment of the vane invaginates (red arrow in Fig. 3D). A small superficial cluster of cells just posterior to this invagination (gray arrow in Fig. 3D), in a position where the Hoyle organ has been identified (Arnold, 1990; Cyran et al., 2018), stains more brightly with the Calcofluor dye (Fig. 3D) than other surrounding cells. The posterior invagination is no longer present prior to hatching (Fig. 3E). The thinner layers of chitin in the lateral vane stain more faintly than the thicker, central rachis. At hatching, the entire pen structure appears to be a miniature form of the pen in the adult shown above (Fig. 1A). In the hatchling pen, the skeletal muscle of the mantle (red area in Fig. 3F, inset) attaches along the lateral edges of the pen (green area in Fig. 3F, inset). The pen expands laterally, beneath the edges of the skeletal muscle of the mantle. In embryos, as in adults (Ruiz-Cooley et al., 2010; Lorrain et al., 2011), the anterior region of the pen elongates more rapidly than the vane.

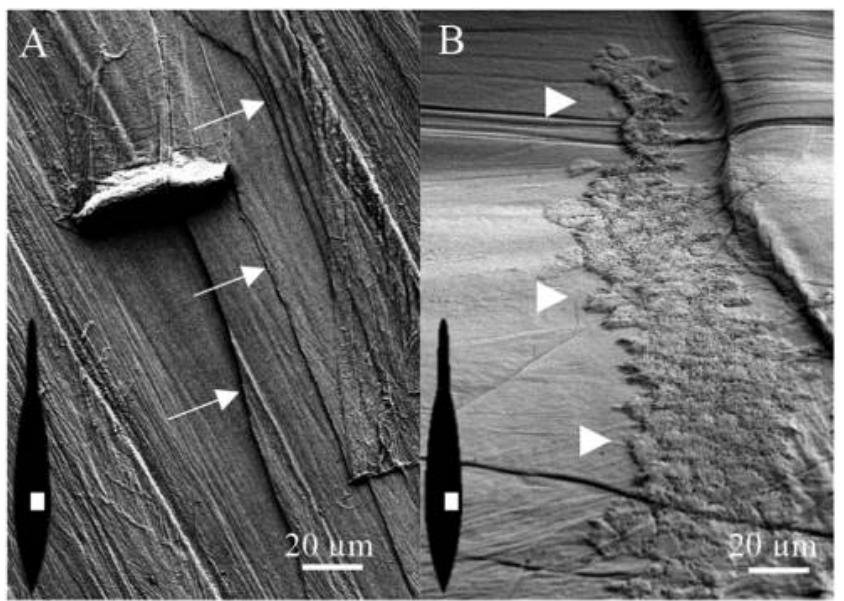

Figure 2. Scanning electron micrograph of adult Doryteuthis pealeii pen surface. (A) The pen is composed of multiple layers, identified by white arrows. (B) A region of the shell sac epithelium remains attached to the pen. White triangles identify the left perimeter. The illustrations within the images show the pen orientation (black) and the region (white) used to collect the micrographs in (A) and (B). 


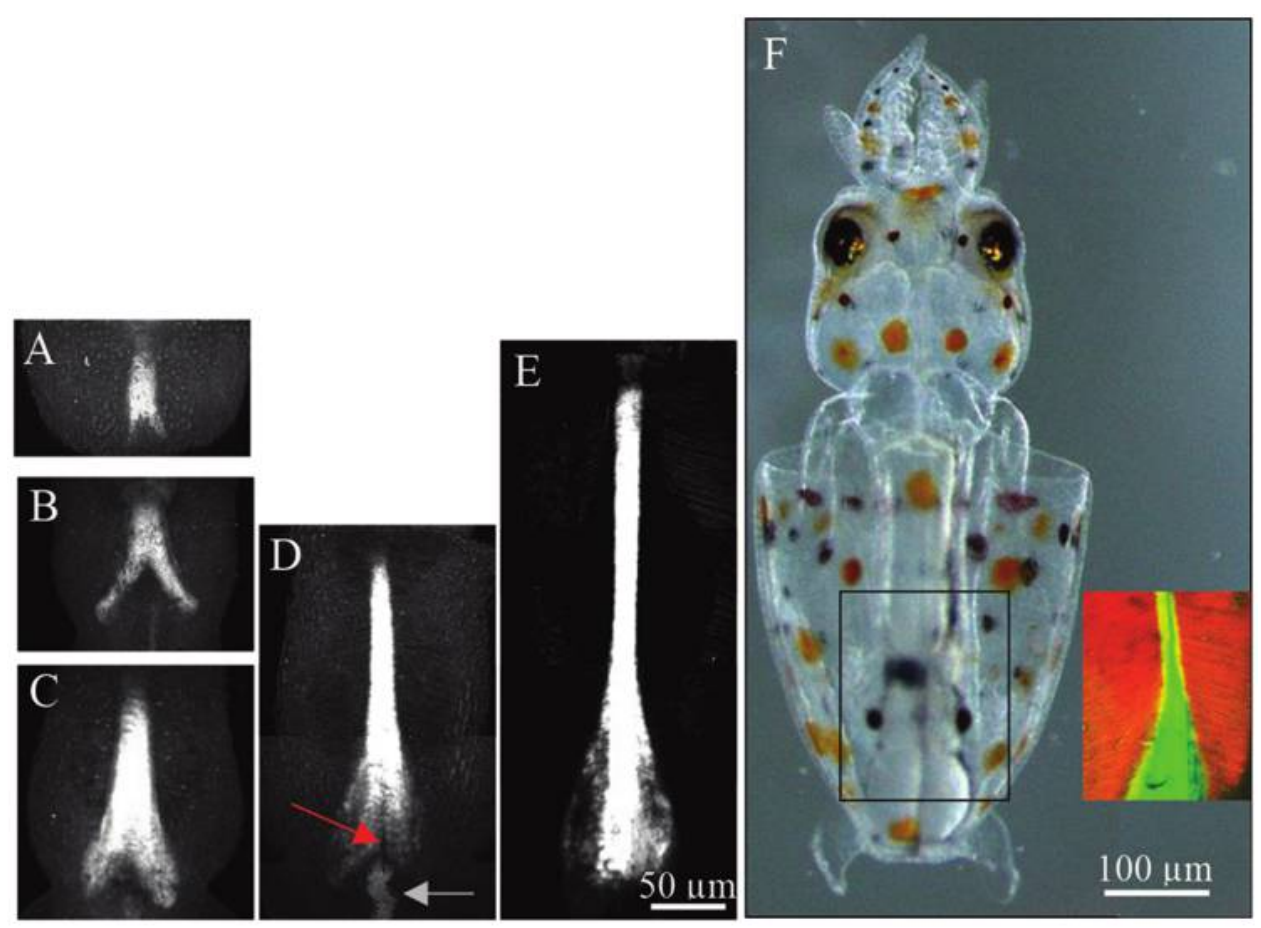

Figure 3. Elongation of the developing Doryteuthis pealeii pen. Fluorescence imaging of Calcofluor white reveals pen development in fixed embryos. (A-C) Early stages show elaboration of chitin toward the anterior and the posterior vane. (D, E) In later stages, the anterior extends significantly longer while the vane expands and rounds off along the posterior edge. At stage 28, the posterior region of the pen has an invagination (red arrow); a superficial cluster of cells on the epidermis stains with Calcofluor (gray arrow). (F) In the hatchling, the actin filaments of the mantle (red area) attach to the edges of the rachis and expanded vane of the pen (green area), and they do not completely encircle the pen.

\section{Shell sac ion composition}

Figure 1 and 3 show that pens from $D$. pealeii lack significant mineralization. Does the shell sac insulate the pen from mineralization, or do the pen macromolecules prevent mineralization? To begin to address these questions, we determined the inorganic composition of the extracellular fluid surrounding the pen. We found that nearly half the weight of freshly extracted pens was water $(48.5 \% \pm 2.6 \% ; n=10$ whole pens $)$. Compared to squid plasma, which is similar to seawater, the fluid enclosed in the shell sac contained twice the concentration of free $\mathrm{Ca}^{2+}$, the same concentration of $\mathrm{K}^{+}$, and a little more than half as much $\mathrm{Na}^{+}, \mathrm{Mg}^{2+}$, and $\mathrm{Cl}^{-}$(Table 1). Based on the concentration of these inorganic ions, the shell sac fluid was close to $60 \%$ of the osmolality of the squid plasma. The shell sac maintained an ionic environment chemically distinct from the plasma and extracellular fluid in the squid. Despite the lack of mineralization, $\mathrm{Ca}^{2+}$ was enriched in the shell sac, leading us to hypothesize that protein modifications help to prevent mineralization of the pen.

\section{Pen protein extraction and characterization}

As the $\beta$-chitin of the squid pen has emerged as a renewable commercial resource, its associated proteins have been stripped away to enable applications for raw chitin (Ianiro et al., 2014;
Cuong et al., 2016). The proteins have largely been ignored. In order to measure the total contribution of protein to the pen, alkaline hydrolysis of pulverized pens was used to remove proteins (M1 and M2). When the treatment was performed at room temperature, we found that $D$. pealeii pens were composed of $33.9 \% \pm 0.01 \%$ chitin and $66.1 \% \pm 0.01 \%$ nonchitinous material $(n=6)$. The nonchitinous material was dominated by proteins (Hunt and Nixon, 1981). We also performed alkaline hydrolysis at $95^{\circ} \mathrm{C}$, yielding a slightly elevated estimate of nonchitinous material $(71.2 \% \pm 0.5 \% ; n=4)$, which may reflect either a greater hydrolysis of proteins than performed at room temperature or deacetylation of chitin into chitosan.

In order to identify microscopic differences between whole pens with and without proteins (extracted using guanidine), we imaged the lateral edges of the vane of treated pens with SEM. The fiber alignment running top to bottom (Fig. 4) was parallel to the anterior-posterior axis. Under lower magnification $(200 \times)$, the pen surface with proteins (Fig. 4A) was difficult to discriminate from the pen surface without proteins (Fig. 4B). However, under higher magnification $(1500 \times)$, the pen surface with proteins (Fig. 4C) was rough compared to the smooth, glassy appearance of the surface of the pen obtained in the absence of proteins (Fig. 4D).

We further characterized the organic composition of pens by extracting proteins for identification. Protein extraction with 
Table 1

Ionic composition of select fluids

\begin{tabular}{lcccc}
\hline \hline \multicolumn{1}{c}{ Solute } & Seawater $^{\mathrm{a}}$ & Squid plasma $^{\mathrm{a}}$ & Shell sac & Extrapallial fluid $^{\mathrm{b}}$ \\
\hline $\mathrm{Na}^{+}$ & 460 & 440 & $235.6 \pm 21.7$ & $442.3 \pm 16.2$ \\
$\mathrm{~K}^{+}$ & 10 & 20 & $21.1 \pm 3.2$ & $9.5 \pm 1.1$ \\
$\mathrm{Ca}^{2+}$ & 10 & 10 & $19.5 \pm 1.0$ & $11.1 \pm 1.4$ \\
$\mathrm{Mg}^{2+}$ & 53 & 54 & $36.4 \pm 3.2$ & $58.3 \pm 6.6$ \\
$\mathrm{Cl}^{-}$ & 540 & 560 & $311.5 \pm 27.3$ & $476.3 \pm 14.4$ \\
$\mathrm{SO}_{4}^{2-}$ & $\ldots$ & $\ldots$ & $2.5 \pm 0.6$ & $23.6 \pm 3.0$ \\
$\mathrm{PO}_{4}^{-}$ & $\ldots$ & $\ldots$ & $4.3 \pm 1.4$ & $\ldots$ \\
\hline
\end{tabular}

${ }^{a}$ Hodgkin, 1958

${ }^{\mathrm{b}}$ Crenshaw, 1972.

either guanidine or acidic urea led to similar banding patterns when compared with SDS-PAGE; however, guanidine treatment showed greater quantities of extracted protein. Therefore, guanidine treatment was used for further extractions.

Using the partial sequences from the shell sac transcriptome and multiple iterations of protein extraction methods, we explored the identity of pen proteins by using MS/MS of proteins excised from polyacrylamide gels. Removal of proteins from pens (M1) led to identification of 309 shell sac sequences from the protein fragments. We also observed that guanidine extraction removed only $36.3 \% \pm 0.02 \%(n=3)$ of the mass of nonchitinous material, compared to alkaline hydrolysis, leading us to hypothesize that a majority of the pen proteins are either covalently cross-linked to the chitin fibers or immobilized within the chitin nanofibril meshwork. Some of the most abundant proteins of this extraction include actin, myosin, and tropomyosin, along with a long list of other intracellular proteins, indicating substantial cellular material from tissues outside of the pen, including the mantle muscle.

In order to reduce proteins from tissues outside of the pen, we took a more rigorous approach to removing them by scrubbing pens with a plastic bristled brush (M2). After this treatment, the number of intracellular proteins was significantly reduced and is shown in Figure 5. The identified pen proteins are listed in Table S1 (available online), according to the area of the protein fragments in the ion chromatograms. Of the 144 unique transcripts identified by protein fragments, more than $60 \%$ are intracellular proteins, leading us to conclude that the brushed pens still contained a substantial amount of attached cellular material. This statement is supported by SEM in Figure 2B.

A further attempt to remove intracellular proteins was made by removing the superficial proteins with repeated rinses of guanidine, followed by rinses with acetate buffer ( $\mathrm{pH} 4.5)$. The remaining material was submerged in $10 \mathrm{mmol} \mathrm{L}^{-1}$ periodate in acetate buffer, which oxidizes carbon-carbon bonds of the chitin glucose backbone (Vold and Christensen, 2005) and which should release proteins trapped between the chitin nanofibrils. With these combined treatments, only 20 proteins were extracted from the interior of the pulverized pen fragments. All of these proteins were identified in the two earlier protein
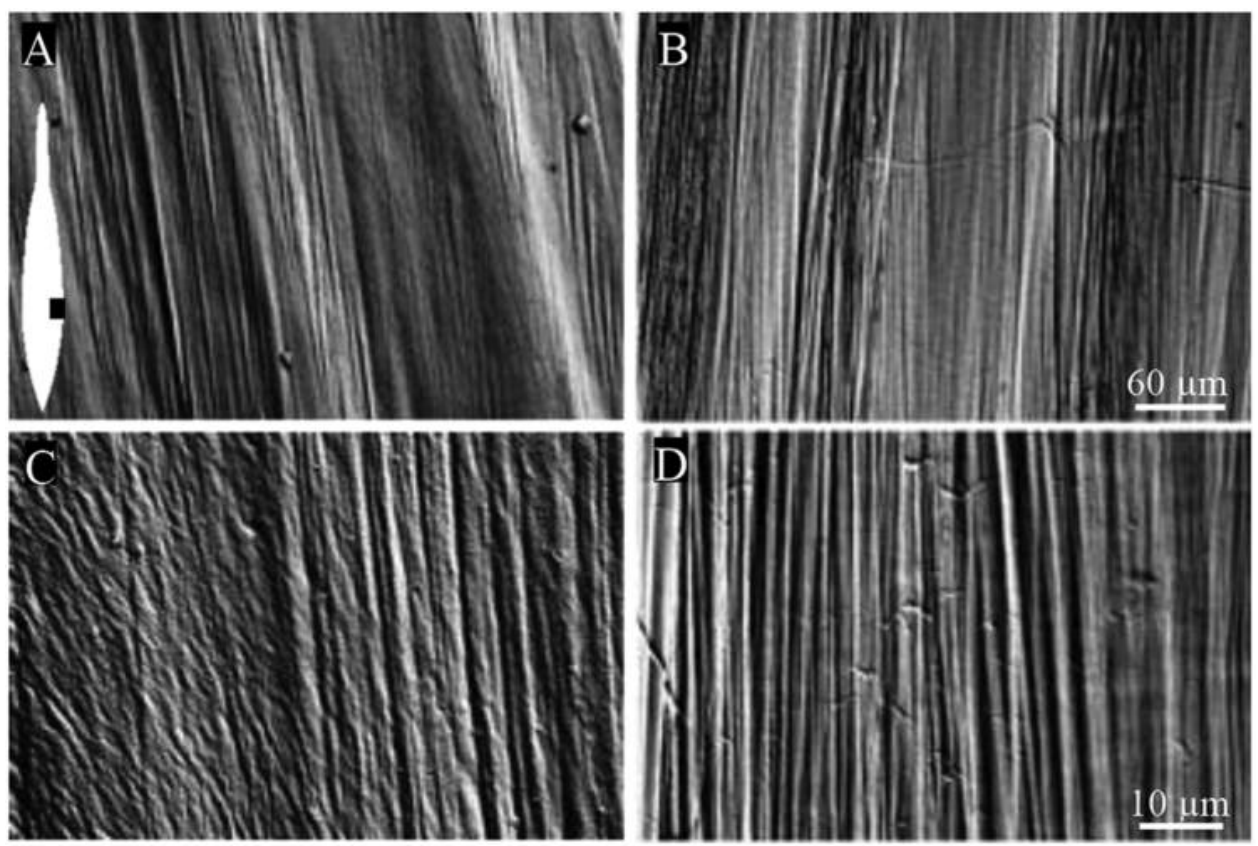

Figure 4. Surface structure of the lateral pen of Doryteuthis pealeii in the presence and absence of proteins. (A, B) Low-magnification scanning electron micrograph shows little difference in surface structure between an untreated pen (A) and a protein-extracted pen (B). The inset in (A) shows an illustration of the pen (white) with similar orientation and the region of the pen (black) used to collect the micrographs. (C, D) Higher magnification shows a change from a roughened, fibrous coating in the untreated pen $(C)$ to a smooth, glassy appearance in the protein-extracted pen (D). 


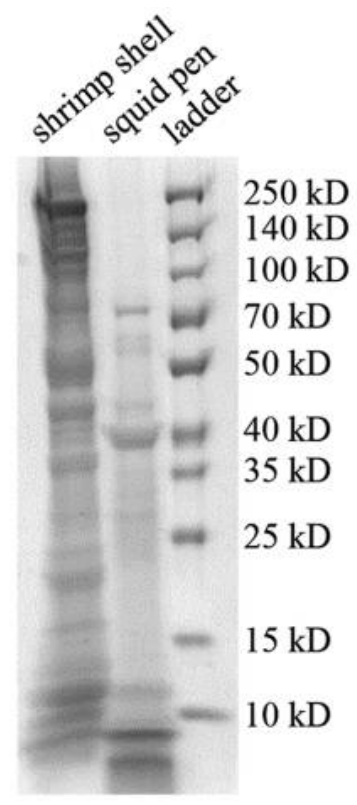

Figure 5. Sodium dodecyl sulfate polyacrylamide gel electrophoresis of guanidine-extracted proteins from Doryteuthis pealeii pens and Litopenaeus setiferus shells. The extracted proteins from the pens are shown for comparison against extracted proteins from the white shrimp shell, a mineralized chitinous structure.

extractions and are in relatively high abundance in the whole pen protein extraction listed in Table S1 (available online). Table S2 (available online) contains the protein fragments used in combination with the transcriptome to identify the proteins.

In order to further explore the possibility that other pen proteins may be covalently linked to the chitin nanofibrils, we used hydroxylamine, a treatment that cleaves peptide bonds between asparagine and glycine. This method was successful in identifying proteins covalently cross-linked in the beak of the Humboldt squid (Tan et al., 2015). After removing noncovalently bound proteins with guanidine, pulverized pens (M2) were exposed to hydroxylamine, and the protein fragments were isolated and identified. Covalently bound proteins that were not liberated by the guanidine treatments alone, but that were released due to hydroxylamine treatment, would yield unique proteins. However, no unique proteins were identified in this manner. The results of the periodate- and hydroxylaminebased protein extractions led us to conclude that pen proteins are not covalently bound to the chitin, but rather they remain trapped within the tight, fibrous mesh of the chitin nanofibrils and are not fully released by guanidine treatments.

We classified the 20 predicted proteins (PPs) embedded within the pen into 6 different groups: chitin associated, unknown, protease inhibitor, intracellular, protease, and extracellular matrix. We designated the proteins as PPs because of the fact that the transcriptome nucleotide sequences used to identify them were incomplete. In Table 2, PPs are listed first by group and then by relative abundance within that group, according to the mass spectrometry results. Except for PP 1 and the unknown PPs 9-13, the e-scores for amino acid alignment were less than $10^{-10}$ when compared with sequences on UniProt.

The largest group of PPs, $1-8$, is associated with chitin binding or chitin modification, including chitin cross-linking proteins, a chitinase, and a chitin deacetylase. PPs 1 and 4-8 are homologous to proteins with multiple chitin-binding domains (CBDs) but have weaker homology than chitinases or chitin deacetylases, which may identify them as chitin crosslinking proteins. PPs 1, 4, and 7 are homologous to proteins with 10-25 CBDs. The number of CBDs contained within each of the partial transcripts is listed in parentheses under the "Conserved domains" column for the chitin-binding proteins in Table 2.

The translated open reading frame for PP 1, in Figure 6, contains four CBDs and has highest homology with chitinbinding proteins from the sea squirt Ciona intestinalis. Regions of PP 1 do not show sufficient homology with the conserved chitin-binding type 2 domains (CBD2) to be flagged during a conserved domain search. In part, this may be due to the fact that the CBDs of PP 1 contain four cysteines rather than six. The cysteines form disulfide bridges that are reported to promote binding to the chitin (Shen and Jacobs-Lorena, 1998; Tjoelker et al., 2000). The amino acid alignment shows a repeating, conserved $\mathrm{M} * \mathrm{CAPG}$ region just before the fourth cysteine of the Ciona sequences (where an asterisk represents amino acids with aromatic side groups).

PPs 5 and 8 are chitin-binding proteins with sequence homology with proteins involved with nacre formation and nucleating the inorganic component of mollusc shells (Blank et al., 2003), and a chitin-binding protein found in the sclerotized beak of the giant squid (Tan et al., 2015), respectively. While PP 6 has the greatest homology with proteins containing domains with hydrolase activity and activity for hydrolyzing O-glycosyl compounds, common to the chitin-modifying proteins, the partial sequence of the transcript contains only a CBD2, so we list it conservatively as a chitin-binding protein.

Two other chitin-associated proteins have homology with enzymes leading to chitin hydrolysis or deacetylation. PP 2, the protein with the fifth-greatest relative abundance, is homologous to a deacetylase. Chitin deacetylases remove the twocarbon acetyl group and expose an amine that is positively charged at neutral $\mathrm{pH}$. This may help prevent mineralization of the pen by repelling $\mathrm{Ca}^{2+}$, but it also might promote ionic interactions with surrounding negatively charged proteins. In the absence of a deacetylase, insect cuticle is less compact, and animals die at molting (Yu et al., 2016). PP 3 has a conserved glycoside hydrolase domain (GH18) common to chitinases and also a CBD. While this protein has homology with chitotriosidase, a chitinase involved with the innate immune system in vertebrates, we think that its relative abundance and location within the pen indicates that it may be playing a role in the remodeling of the pen chitin. Whether it still acts as a chitinase 


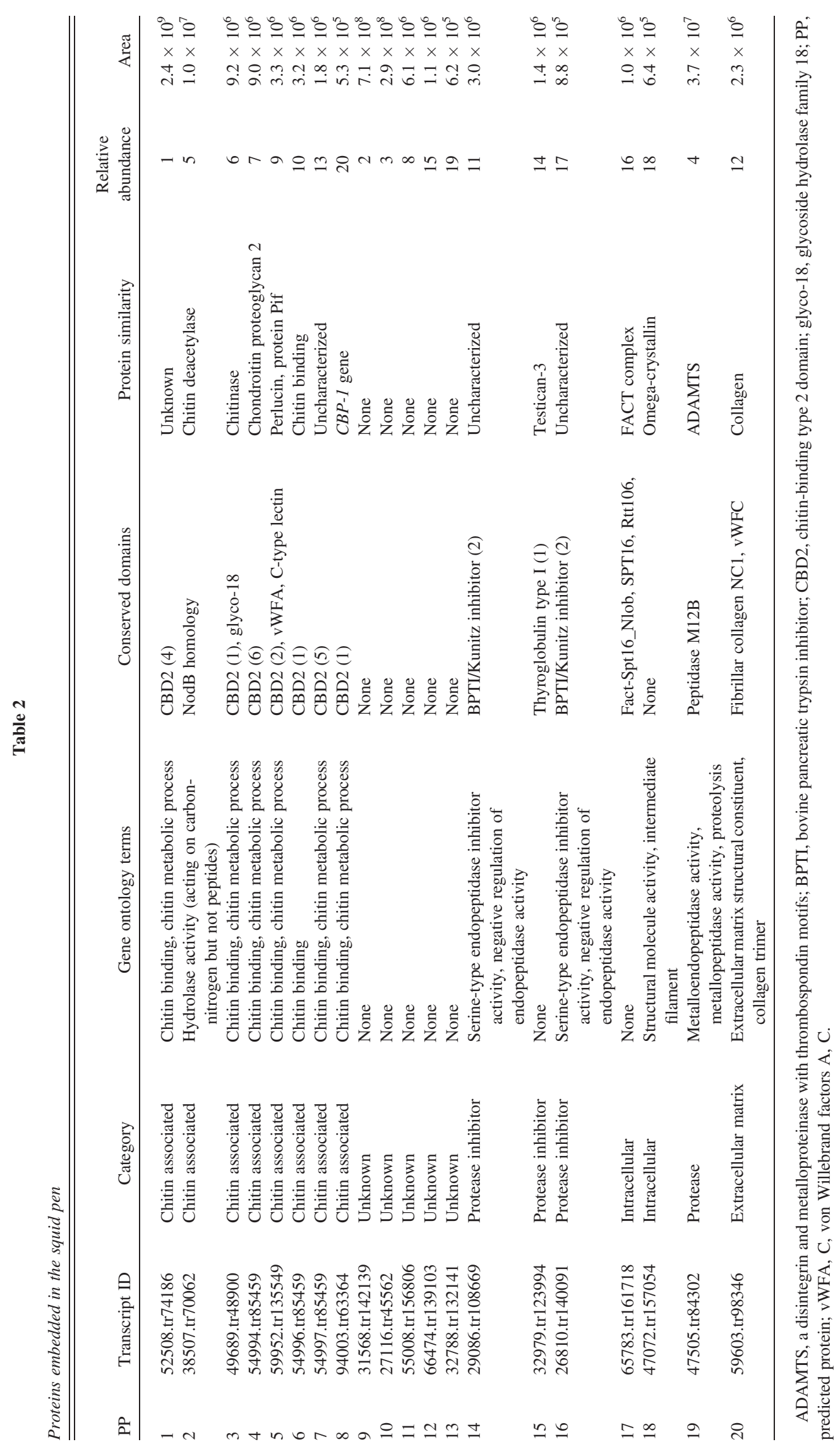

This content downloaded from 128.128.132.017 on August 29, 2019 10:37:00 AM

All use subject to University of Chicago Press Terms and Conditions (http://www.journals.uchicago.edu/t-and-c). 


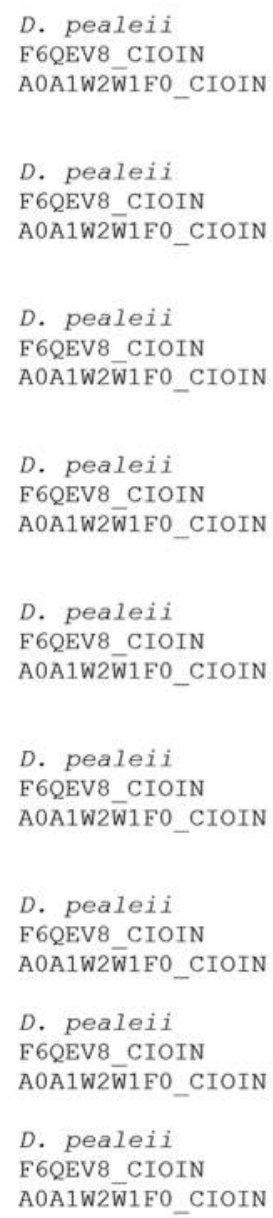

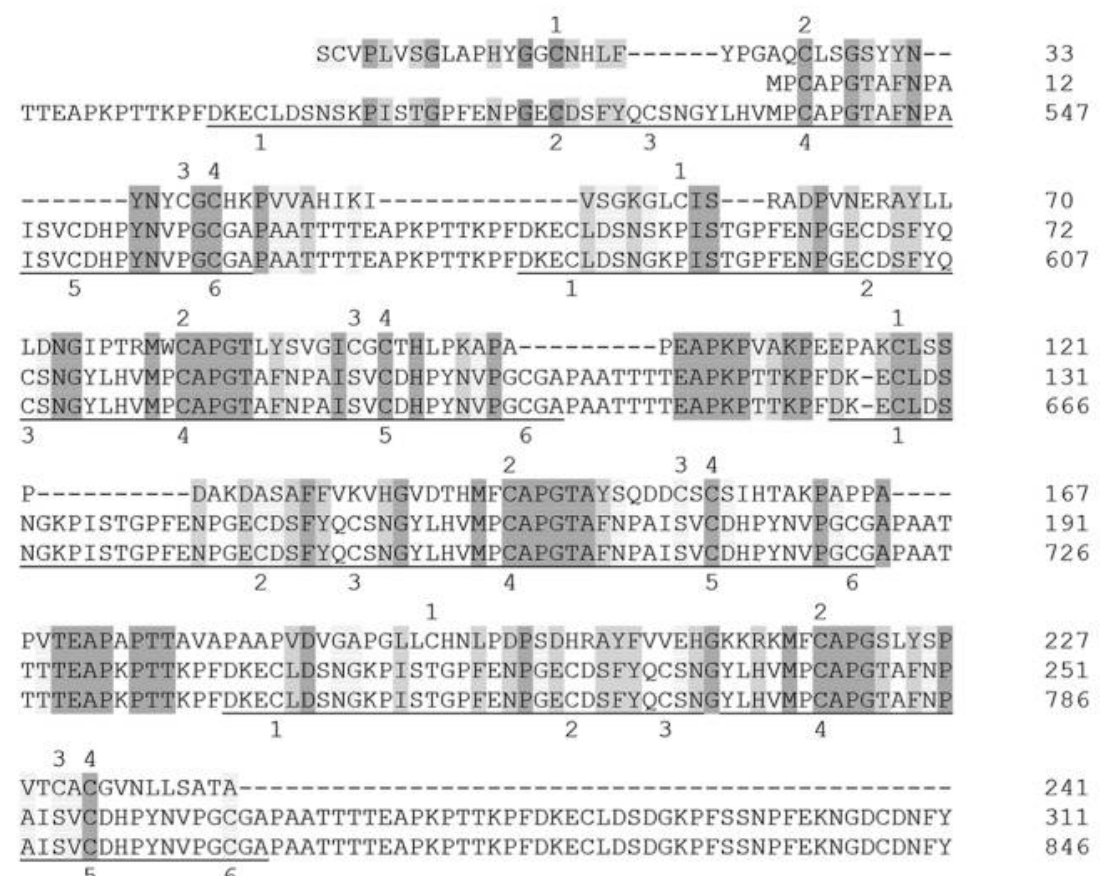

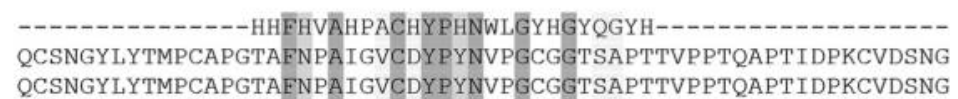

KPMSTGPFEKPGDCDHFYQCSNGYLHVMPCGPGTAFNPAISVCDWPYNVPGCGAPAATTT KPMSTGPFEKPGDCDHFYQCSNGYLHVMPCGPGTAFNPAISVCDWPYNVPGCGAPAATTT

TEAPKTTSPPFNAQCVDSNGKPMSTGPFEKPEDCDNFY YQCSNGYLHTMPCAPGTAFNPAI TEAPKTTSPPFNAQCVDSNGKPMSTGPFEKPEDCDNFȲQCSNGYLHTMPCAPGTAFNPAI

Figure 6. Sequence alignment between the protein with greatest relative abundance in the Doryteuthis pealeii pen (predicated protein 1) and homologous Ciona intestinalis sequences (F6QEV8 length 570, A0A1W2W1F0 length 1105). Numbers at the end of each line indicate the amino acid position in the sequence. Dark shading represents conserved residues, while lighter shading represents conservation between groups with strongly similar properties. The underlined regions are repeating chitin-binding type 2 domains (CBD2). Numbers above the $D$. pealeii sequence mark the four conserved cysteine residues, while the numbers below the $C$. intestinalis sequences mark the six conserved cysteine residues in the CBD2.

deep within the pen or whether it has some important secondary structural role remains unanswered.

The second-largest group contains five PPs, 9-13, and is composed of proteins that have low homology with any known proteins, based on low e-scores, or that are homologous to other uncharacterized proteins with no conserved domains. Large numbers of shell proteins remain unknown for similar reasons (Mann and Jackson, 2014; Jackson et al., 2015). Proteins with the second- and third-greatest relative abundance belong to this category.

Three proteins, PPs 14-16, have homology with protease inhibitors. PPs 14 and 16 contain multiple bovine pancreatic trypsin inhibitor BPTI/Kunitz domains. These domains are involved with inhibition of serine proteases, act as anti-coagulant factors, and are involved in defense against microbial pathogens (Ranasinghe and McManus, 2013). A protein with similar domains is required for collagen biosynthesis in the chitinous cuticle of Caenorhabditis elegans (Stepek et al., 2010). PP 15, however, has homology with testican-3, a secreted proteoglycan involved in regulation of extracellular protease cascades (Nakada et al., 2001).

Two intracellular proteins, PPs 17 and 18, were found in relatively low abundance after the periodate treatment. PP 17, a FACT (Facilitates Chromatin Transactions) complex, is a nuclear histone chaperone involved with replication, transcription, and DNA repair (Winkler and Luger, 2011). In the pen, the FACT complex may be a result of remaining shell sac epithelium. PP 18, an intermediate filament protein, has homology with omega crystallin, a protein found in the lens and cornea of the eye (Vasiliou et al., 2013).

PP 19 appears to be a lone protease embedded in the pen from the ADAMTS family (a disintegrin and metalloproteinase 
with thrombospondin motifs) and is present in fourth-greatest relative abundance. These proteases are secreted proteins known for modulating extracellular proteins, including processing of procollagen to collagen and cleavage of extracellular proteoglycans and the von Willebrand factor (Porter et al., 2005). PP 19 has the highest homology with ADAMTS8, which has been shown to cleave extracellular proteoglycans and possess anti-angiogenic properties (Vazquez et al., 1999; CollinsRacie et al., 2004). ADAMTS proteins are involved with ecdysis, shedding of the outer cuticle, and metamorphosis in the silkworm (Ote et al., 2005; Kawasaki et al., 2018). Remodeling of the squid pen may be similar to remodeling of the insect cuticle.

PP 20 is homologous to collagen, an extracellular matrix protein found in load-bearing structures such as tendons or ligaments. While collagen was inferred as a surface protein in the pen of Illex argentinus (Wu et al., 2003), our results indicate that collagen is also embedded within the pen. Its relative abundance increased significantly between total pen protein (Table S1, available online) and proteins extracted after periodate treatment (Table 2). This indicates that collagen is found in relatively higher abundance within the pen than on the surface of the pen. PP 20 may interact with PP 5, which has both chitin- and collagen-binding domains, to cross-link chitin and collagen within the pen.

A number of other interesting proteins surrounding the pen were identified prior to the periodate extraction of proteins. These proteins are listed in Table 3, including seven more chitin-associated proteins, two more proteins with BPTI/ Kunitz domains, many forms of collagen, and proteins with homology with shell matrix proteins, including galaxin and nidogen.

\section{Discussion}

Microscopic examination of adult and embryonic pens of Doryteuthis pealeii supports the absence of sclerotization or mineralization, as found in pens from other species of squid (Subhapradha et al., 2013). The birefringence of the D. pealeii pen (Fig. 1B) and the scanning electron micrographs (Figs. 2, 4) support an anterior-posterior alignment of the chitin-protein composite along the rachis, the narrow anterior portion of the pen, and the edges of the vane, similar to the alignment in other species (Yang et al., 2014). The pen does not show the "twisted plywood" arrangement of crustacean exoskeletons (Raabe et al., 2005), and it is not porous or pitted, as found in insects (Schroder-Turk et al., 2011; Kaya and Baran, 2015). In a single layer, the chitin nanofibrils appear in close juxtaposition, even after removal of surface proteins (Fig. 4D).

The lamellar structure of the pen (Fig. 2A) is very similar to that found in the near-tip region of the squid beak (Miserez et al., 2007) and the shells of the sea snail (Bezares et al., 2012), with very little space between layers. The tight arrange- ment of nanofibrils in a single layer remains even after alkaline hydrolysis of proteins; however, the layers of chitin now appear disconnected (Wu et al., 2003; Ianiro et al., 2014). Based on these observations, we hypothesize that chitin nanofibril interactions between layers have greater dependence on proteins than nanofibril interactions within a layer.

We have shown that the embryonic shell sac, mantle, and pen are very thin, enabling three-dimensional imaging of pen morphology using Calcofluor white (Fig. 3) in combination with multi-photon microscopy. In vivo gene knockdown and Calcofluor imaging will provide insight into the function of some of the proteins involved with pen construction. Moreover, transgene expression of fluorescently tagged proteins should enable stage-dependent localization of important proteins.

The ionic environment in which chitin nanofibrils and proteins assemble is distinct from squid plasma and extracellular fluid (Table 1). The inorganic solutes in the plasma with the greatest osmotic activity, $\mathrm{Na}^{+}$and $\mathrm{Cl}^{-}$, are reduced in the pen. While this may indicate that the shell sac fluid is hypotonic to plasma, it may also indicate that these inorganic solutes have been replaced with small organic solutes (Wright, 1995). Further analysis could confirm this hypothesis.

An unexpected finding is that the $\mathrm{Ca}^{2+}$ concentration surrounding the non-mineralized pen is twice as great as the $\mathrm{Ca}^{2+}$ concentration in the extrapallial fluid between the shell and the mantle epithelium of three marine bivalve molluscs that produce mineralized shells (Table 1; Crenshaw, 1972). Even with the higher surrounding $\mathrm{Ca}^{2+}$ concentration, the pen remains uncalcified. This may be due to the relatively larger fraction of hydrophobic amino acids and reduction of the acidic amino acids, as reported in pens from other species (Hackman, 1960; Hunt and Nixon, 1981; Wu et al., 2003; Cuong et al., 2016). For comparison, mineralized mollusc shells and bone contain proteins enriched with acidic amino acids and amino acids containing negatively charged sulfates and phosphates that are used to concentrate $\mathrm{Ca}^{2+}$ and that are necessary for nucleation on the structured carboxylate domains (Weiner and Hood, 1975; Addadi et al., 1987; George and Veis, 2008). Consistent with this hypothesis is that the free sulfate concentration in the pen is 10-fold lower than the average concentration in the extrapallial fluid of the bivalve molluscs listed in Table 1 (Crenshaw, 1972). Further experiments to obtain full-length pen proteins for $D$. pealeii will be necessary to confirm this hypothesis.

Chitin nanofibrils of pens have been characterized as being surrounded by proteins with helical and coiled-coil structures (Yang et al., 2014). We identified seven proteins embedded in the pen with these properties, including collagen, which is a supercoiled triple helix (Beck and Brodsky, 1998). We also found other proteins that have $\alpha$-helical secondary structures, including ADAMTS (Gerhardt et al., 2007), chitinase (Hahn et al., 2000), chitin deacetylase (Liu et al., 2017), proteins with Kunitz domains (Dai et al., 2012), and omega crystallin (Vasiliou et al., 2013). Additional helical or coiled secondary 


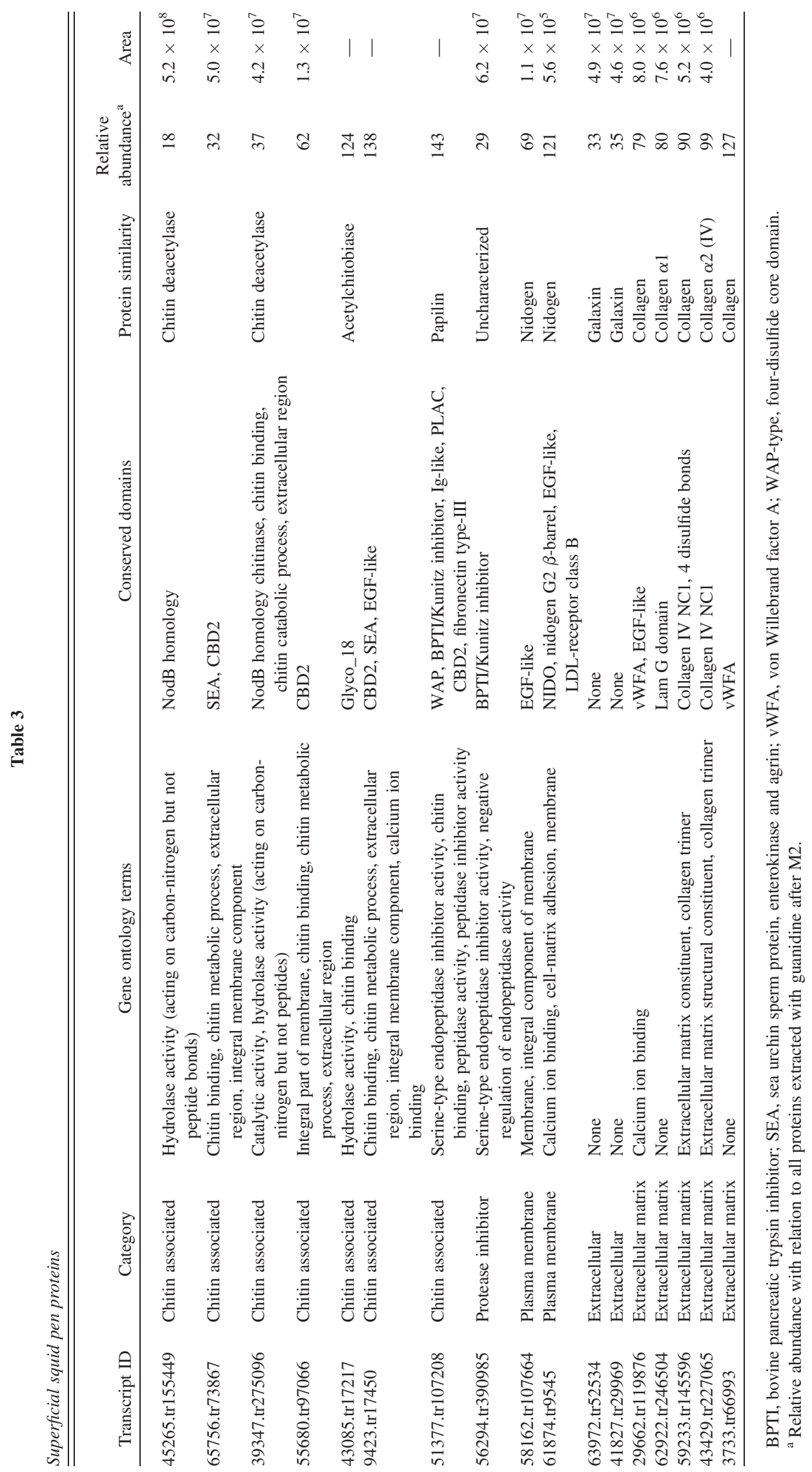

This content downloaded from 128.128.132.017 on August 29, 2019 10:37:00 AM 
structures may be found in the five proteins that have not been identified.

The largest groups of proteins associated with the pen are the chitin-associated proteins. Seven of the 20 embedded proteins (Table 2) and an additional 4 proteins associated with the surface of the pen (Table 3 ) have CBDs. PP 1, the protein embedded in the pen with the greatest relative abundance, appears to possess multiple CBDs but does not appear to have catalytic domains for remodeling the secreted chitin, similar to five other proteins embedded in the pen. Additionally, no unique proteins were extracted from the pulverized pen during periodate or hydroxylamine treatment, leading us to conclude that proteins in the pen are not covalently crosslinked to chitin. Considering that the strength of the pen is derived from its careful construction of chitin and protein in the absence of sclerotization, a number of different chitin-binding proteins might have different uses. For example, shorter chitinbinding proteins with few CBDs might cross-link individual chitin nanofibrils, while longer proteins with many more CBDs might bundle multiple chitin nanofibrils, as postulated for the chitinous peritrophic matrix of the invertebrate intestinal lining (Merzendorfer et al., 2016).

We hypothesize that a significant amount of chitin and protein modification is occurring after the macromolecules are released from the ventral shell sac. This is based on the chitinmodifying proteins that were present, embedded in the pen and on the surface of the pen, and also the presence of a protease, known for modulating extracellular matrix proteins, and protease inhibitors. Understanding these mechanisms will help to clarify the complex biomolecular self-assembly used to construct such a highly polarized structure by so many different cells in the epithelium.

In the pens of Loligo vulgaris, proline was reported to be in its hydrophobic form and was not hydroxylated (Hackman, 1960; Hunt and Nixon, 1981), as commonly found in collagen. This may be due to the fact that proline is enriched in the more abundant proteins in the pen and overwhelms the hydroxyproline from the collagen, which appears at relatively lower levels in the pen (Table 2). Alternatively, the proline on the collagen may not be hydroxylated. Microbial collagen and recombinant collagen still form triple helices in the absence of hydroxylated proline (Perret et al., 2001; Mohs et al., 2007). The increased hydrophobicity of the collagen in this state may increase interactions with the hydrophobic acetyl groups of chitin and also reduce hydration of collagen, although it does not prevent folding. Like proline, glycine is also enriched (Hackman, 1960; Hunt and Nixon, 1981; Wu et al., 2003; Cuong et al., 2016). Proline and glycine are often found at turns or in protein loop structures, consistent with the observation that pen proteins surrounding the chitin have helical and coiled-coil structures (Yang et al., 2014).

When compared to other chitinous structures, the pen appears to be one of the simplest arrangements of chitin and protein that is flexible and still maintains its strength. The protein composition of the squid pen shares a great deal of similarity with proteins from other chitinous structures. However, in the absence of sclerotization and mineralization, the proteins are easier to collect, identify, and study. Further studies will help elucidate the complex mechanisms of chitin-protein structure and function and the self-assembly that occurs to make the highly organized pen. Comparison of uncalcified squid pens with calcified squid pens (Subhapradha et al., 2013) or cuttlefish bone (Le Pabic et al., 2017) would also be useful in understanding protein modifications used to promote biomineralization. A completed D. pealeii genome will be most beneficial in helping to characterize and identify the unknown proteins described above.

\section{Acknowledgments}

We thank John Dowling for financial support. We thank Kasia Hammar and Louie Kerr of the Marine Biological Laboratory Central Microscopy Facility for help obtaining scanning electron micrographs. We thank Bogdan Budnik and Renee Robinson from the Mass Spectrometry and Proteomics Resource Laboratory for their help and advice with protein identification. We thank Shin-Yi Marzano and Chenchen Feng of South Dakota State University for help with rapid amplification of cDNA ends. Funding for this work was provided by the Eugene and Millicent Bell Fellowship Fund in Tissue Engineering (MAM), an Agriculture and Biological Sciences Undergraduate Research Award (KSB), National Institutes of Health grant R01 GM101701 (MS), National Science Foundation grant IOS1557748 (JJCR), and Israel-United States Binational Science Foundation 2013094 (JJCR).

\section{Literature Cited}

Addadi, L., J. Moradian, E. Shay, N. G. Maroudas, and S. Weiner. 1987. A chemical model for the cooperation of sulfates and carboxylates in calcite crystal nucleation: relevance to biomineralization. Proc. Natl. Acad. Sci. U.S.A. 84: 2732-2736.

Andersen, S. O. 2010. Insect cuticular sclerotization: a review. $\underline{\text { Insect }}$ Biochem. Mol. Biol. 40: 166-178.

Andrews, S. 2010. FastQC: a quality control tool for high throughput sequence data. [Online]. Available: http://www.bioinformatics.babraham .ac.uk/projects/fastqc [2019, May 31].

Arnold, J. M. 1965. Normal embryonic stages of the squid Loligo pealii (Lesueur). Biol. Bull. 128: 24-32.

Arnold, J. M. 1990. Embryonic development of the squid. Pp. 77-90 in Squid as Experimental Animals, D. L. Gilbert, W. J. Adelman, and J. M. Arnold, eds. Springer, Boston.

Beck, K., and B. Brodsky. 1998. Supercoiled protein motifs: the collagen triple-helix and the $\alpha$-helical coiled coil. J. Struct. Biol. 122: 17-29.

Bezares, J., R. J. Asaro, and V. A. Lubarda. 2012. Core structure of aligned chitin fibers within the interlamellar framework extracted from Haliotis rufescens nacre. Part I: Implications for growth and mechanical response. Theor. Appl. Mech. 39: 343-363.

Bizikov, V. A. 1995. Growth of Sthenoteuthis oualaniensis, using a new method based on gladius microstructure. ICES Mar. Sci. Symp. 199: 445458. 
Blank, S., M. Arnoldi, S. Khoshnavaz, L. Treccani, M. Kuntz, K. Mann, G. Grathwohl, and M. Fritz. 2003. The nacre protein perlucin nucleates growth of calcium carbonate crystals. J. Microsc. 212: 280-291.

Bolger, A. M., M. Lohse, and B. Usadel. 2014. Trimmomatic: a flexible trimmer for Illumina sequence data. Bioinformatics 30: 2114-2120.

Chaussard, G., and A. Domard. 2004. New aspects of the extraction of chitin from squid pens. Biomacromolecules 5: 559-564.

Cole, A. G., and B. K. Hall. 2009. Cartilage differentiation in cephalopod molluscs. Zoology 112: 2-15.

Collins-Racie, L. A., C. R. Flannery, W. Zeng, C. Corcoran, B. AnnisFreeman, M. J. Agostino, M. Arai, E. DiBlasio-Smith, A. J. Dorner, K. E. Georgiadis et al. 2004. ADAMTS-8 exhibits aggrecanase activity and is expressed in human articular cartilage. Matrix Biol. 23: 219-230.

Cortizo, M. S., C. F. Berghoff, and J. L. Alessandrini. 2008. Characterization of chitin from Illex argentinus squid pen. Carbohydr. Polym. 74: $10-15$.

Crenshaw, M. A. 1972. The inorganic composition of molluscan extrapallial fluid. Biol. Bull. 143: 506-512.

Crusoe, M. R., H. F. Alameldin, S. Awad, E. Bucher, A. Caldwell, R. Cartwright, A. Charbonneau, B. Constantinides, G. Edvenson, S. Fay et al. 2015. The khmer software package: enabling efficient nucleotide sequence analysis. [Online]. Available: http://dx.doi.org/10 .12688/f1000research.6924.1 [2019, May 31].

Cuong, H. N., N. C. Minh, N. V. Hoa, and T. S. Trung. 2016. Preparation and characterization of high purity $\beta$-chitin from squid pens (Loligo chenisis). Int. J. Biol. Macromol. 93: 442-447.

Cyran, N., A. Palumbo, W. Klepal, E. A. G. Vidal, Y. Staedler, J. Schönenberger, and J. von Byern. 2018. The short life of the Hoyle organ of Sepia officinalis: formation, differentiation and degradation by programmed cell death. Hydrobiologia 808: 35-55.

Dai, S.-X., A. Zhang, and J. Huang. 2012. Evolution, expansion and expression of the Kunitz/BPTI gene family associated with long-term blood feeding in Ixodes scapularis. BMC Evol. Biol. 12: 4.

Das, S. N., J. Madhuprakash, P. V. S. R. N. Sarma, P. Purushotham, K. Suma, K. Manjeet, S. Rambabu, N. E. El Gueddari, B. M. Moerschbacher, and A. R. Podile. 2015. Biotechnological approaches for field applications of chitooligosaccharides (COS) to induce innate immunity in plants. Crit. Rev. Biotechnol. 35: 29-43.

Di Martino, A., M. Sittinger, and M. V. Risbud. 2005. Chitosan: a versatile biopolymer for orthopaedic tissue-engineering. Biomaterials 26: 5983-5990.

Fernandez, J. G., and D. E. Ingber. 2013. Bioinspired chitinous material solutions for environmental sustainability and medicine. Adv. Funct. Mater. 23: $4454-4466$.

Fernandez, J. G., and D. E. Ingber. 2014. Manufacturing of large-scale functional objects using biodegradable chitosan bioplastic. Macromol. Mater. Eng. 299: 932-938.

Gene Index Project. 2006. SeqClean. [Online]. Dana-Farber Cancer Institute, Harvard University, Cambridge, MA. Available: ftp://occams.dfci .harvard.edu/pub/bio/tgi/software/seqclean/ [2019, June 28].

George, A., and A. Veis. 2008. Phosphorylated proteins and control over apatite nucleation, crystal growth, and inhibition. Chem. Rev. 108: 4670 4693.

Gerhardt, S., G. Hassall, P. Hawtin, E. McCall, L. Flavell, C. Minshull, D. Hargreaves, A. Ting, R. A. Pauptit, A. E. Parker et al. 2007. Crystal structures of human ADAMTS-1 reveal a conserved catalytic domain and a disintegrin-like domain with a fold homologous to cysteinerich domains. J. Mol. Biol. 373: 891-902.

Gosline, J. M., and M. E. DeMont. 1985. Jet-propelled swimming in squids. Sci. Am. 252: 96-103.

Haas, B. J., A. Papanicolaou, M. Yassour, M. Grabherr, P. D. Blood, and J. Bowden. 2013. De novo transcript sequence reconstruction from RNA-seq using the Trinity platform for reference generation and analysis. Nat. Protoc. 8: 1494.
Hackman, R. H. 1960. Studies on chitin. IV. The occurrence of complexes in which chitin and protein are covalently linked. Aust. J. Biol. Sci. 13: 568-577.

Hahn, M., M. Hennig, B. Schlesier, and W. Hohne. 2000. Structure of the jack bean chitinase. Acta Crustallogr. D Biol. Crustallogr. 56: 1096-1099.

Hodgkin, A. L. 1958. The Croonian Lecture: ionic movements and electrical activity in giant nerve fibers. Proc. R. Soc. B Biol. Sci. 148: 1-37.

Hopkins, B., and S. Boletzky. 1994. The fine morphology of the shell sac in the squid genus Loligo (Mollusca: Cephalopoda): features of a modified conchiferan program. Veliger 37: 344-357.

Hunt, S., and A. EI Sherief. 1990. A periodic structure in the "pen" chitin of the squid Loligo vulgaris. Tissue Cell 22: 191-197.

Hunt, S., and M. Nixon. 1981. A comparative study of protein composition in the chitin-protein complexes of the beak, pen, sucker disc, radula and oesophageal cuticle of cephalopods. Comp. Biochem. Physiol. B Biochem. Physiol. 68: 535-546.

Ianiro, A., M. D. Giosia, S. Fermani, C. Samori, M. Barbalinardo, F. Valle, G. Pellegrini, F. Biscarini, F. Zerbetto, M. Calvaresi et al. 2014. Customizing properties of $\beta$-chitin in squid pen (gladius) by chemical treatments. Mar. Drugs 12: 5979-5992.

Jackson, D. J., K. Mann, V. Haussermann, M. B. Schilhabel, C. Luter, E. Griesshaber, W. Schmahl, and G. Worheide. 2015. The Magellania venosa biomineralizing proteome: a window into brachiopod shell evolution. Genome Biol. Evol. 7: 1349-1362.

Kawasaki, H., A. Manickam, R. Shahin, M. Ote, and M. Iwanaga. 2018. Expression of matrix metalloproteinase genes during basement membrane degradation in the metamorphosis of Bombyx mori. Gene 638: $26-35$.

Kaya, M., and T. Baran. 2015. Description of a new surface morphology for chitin extracted from wings of cockroach (Periplaneta americana). Int. J. Biol. Macromol. 75: 7-12.

Lavall, R. L., O. B. G. Assis, and S. P. Campana-Filho. 2007. $\beta$-chitin from the pens of Loligo sp.: extraction and characterization. Bioresour. Technol. 98: 2465-2472.

Le Pabic, C., A. Marie, B. Marie, A. Percot, L. Bonnaud-Ponticelli, P. J. Lopez, and G. Luquet. 2017. First proteomic analyses of the dorsal and ventral parts of the Sepia officinalis cuttlebone. $\underline{\text { J. Proteom. }}$. 150: $63-73$.

Lee, P. N., P. Callaerts, and H. G. de Couet. 2009. The embryonic development of the Hawaiian bobtail squid. Cold Spring Harbor Protoc. 11: pdb.ip77.

Liu, Z., L. M. Gay, T. R. Tuveng, J. W. Agger, B. Westereng, G. Mathiesen, S. J. Horn, G. Vaaje-Kolstad, D. M. F. van Aalten, and V. G. H. Eijsink. 2017. Structure and function of a broadspecificity chitin deacetylase from Aspergillus nidulans FGSC A4. Sci. Rep. 7: 1746.

Lorrain, A., J. Arguelles, A. Alegre, A. Bertrand, J.-M. Munaron, P. Richard, and Y. Cherel. 2011. Sequential isotopic signature along gladius highlights contrasted individual foraging strategies of jumbo squid (Dosidicus gigas). PLoS One 6: e22194.

Ma, H., C. Burger, B. S. Hsiao, and B. Chu. 2011. Ultrafine polysaccharide nanofibrous membranes for water purification. Biomacromolecules 12: $970-976$.

Mann, K., and D. J. Jackson. 2014. Characterization of the pigmented shell-forming proteome of the common grove snail Cepaea nemoralis. BMC Genomics 15: 249.

Marin, F., G. Luquet, B. Marie, and D. Medakovic. 2008. Molluscan shell proteins: primary structure, origin and evolution. Curr. Top. Dev. Biol. 80: 209-276.

Marin, F., B. Marie, S. B. Hamada, P. Ramos-Silva, N. Le Roy, N. Guichard, S. E. Wolf, C. Montagnani, C. Joubert, D. Piquemal et al. 2013. "Shellome": proteins involved in mollusc shell biomineralization-diversity, functions. Pp. 149-166 in Recent Advances in Pearl Research-Proceedings of the International Symposium on 
Pearl Research 2011, S. Watabe, K. Maeyama, and H. Nagasawa, eds. Terrapub, Tokyo.

Merten, V., B. Christiansen, J. Javidpour, U. Piatkowski, O. Puebla, R. Gasca, and H.-J. T. Hoving. 2017. Diet and stable isotope analyses reveal the feeding ecology of the orangeback squid Sthenoteuthis pteropus (Steenstrup 1855) (Mollusca, Ommastrephidae) in the eastern tropical Atlantic. PLoS One 12: 0189691.

Merzendorfer, H., M. Kelkenberg, and S. Muthukrishnan. 2016. Peritrophic matrices. Pp. 255-324 in Extracellular Composite Matrices in Arthropods, E. Cohen and B. Moussian, eds. Springer, Cham, Switzerland.

Miserez, A., Y. Li, J. H. Waite, and F. Zok. 2007. Jumbo squid beaks: inspiration for design of robust organic composites. Acta Biomater. 3: $139-149$.

Mohs, A., T. Silva, T. Yoshida, R. Amin, S. Lukomski, M. Inouye, and B. Brodsky. 2007. Mechanism of stabilization of a bacterial collagen triple helix in the absence of hydroxyproline. J. Biol. Chem. 282: 29757-29765.

Naef, A. 1928. Die Cephalopoden. Part I: Embryologie. Fauna und Flora des Golfes von Neapel und der angrenzenden Meeres-Abschnitte, Vol. 35. R. Friedländer, Berlin.

Nakada, M., A. Yamada, T. Takino, H. Miyamori, T. Takahashi, J. Yamashita, and H. Sato. 2001. Suppression of membrane-type 1 matrix metalloproteinase (MMP)-mediated MMP-2 activation and tumor invasion by testican 3 and its splicing variant gene product, $\underline{\text { N-Tes. Can- }}$ cer Res. 61: 8896-8902.

O'Dor, R. K. 2013. How squid swim and fly. Can. J. Zool. 91: 413-419.

Oldenbourg, R., and M. Shribak. 2010. Microscopes. Pp. 1-62 in Handbook of Optics, 3rd ed., Vol. I, Geometrical and Physical Optics, Polarized Light, Components and Instruments, M. Bass, ed. McGrawHill, New York.

Ote, M., K. Mita, H. Kawasaki, M. Kobayashi, and T. Shimada. 2005. Characteristics of two genes encoding proteins with an ADAMtype metalloprotease domain, which are induced during the molting periods in Bombyx mori. Arch. Insect Biochem. Phvsiol. 59: 91-98.

Perret, S., C. Merle, S. Bernocco, P. Berland, R. Garrone, D. J. S. Hulmes, M. Theisen, and F. Ruggiero. 2001. Unhydroxylated triple helical collagen I produced in transgenic plants provides new clues on the role of hydroxyproline in collagen folding and fibril formation. J. Biol. Chem. 276: 43693-43698.

Porter, S., I. M. Clark, L. Kevorkian, and D. R. Edwards. 2005. The ADAMTS metalloproteinases. Biochem. J. 386: 15-27.

Raabe, D., C. Sachs, and P. Romano. 2005. The crustacean exoskeleton as an example of a structurally and mechanically graded biological nanocomposite material. Acta Mater. 53: 4281-4292.

Ranasinghe, S., and D. P. McManus. 2013. Structure and function of invertebrate Kunitz serine protease inhibitors. Immunology 39: 219-227.

Rasband, W. S. 1997-2018. ImageJ. [Online]. U.S. National Institutes of Health, Bethesda, MD. Available: https://imagej.nih.gov/ij/ [2018, September 1].

Ruiz-Cooley, R. I., E. C. Villa, and W. R. Gould. 2010. Ontogenetic variation of $\delta^{13} \mathrm{C}$ and $\delta^{15} \mathrm{~N}$ recorded in the gladius of the jumbo squid Dosidicus gigas: geographic differences. Mar. Ecol. Prog. Ser. 399: 187198.

Schroder-Turk, G. E., S. Wickham, H. Averdunk, F. Brink, J. D. Fitz Gerald, L. Poladian, M. C. J. Large, and S. T. Hyde. 2011. The chiral structure of porous chitin within the wing-scales of Callophrys rubi. J. Struct. Biol. 174: 290-295.

Shen, Z. C., and M. Jacobs-Lorena. 1998. A type I peritrophic matrix protein from the malaria vector Anopheles gambiae binds to chitin: cloning, expression, and characterization. J. Biol. Chem. 273: 17665-17670.
Stepek, G., G. McCormack, and A. P. Page. 2010. The Kunitz domain protein BLI-5 plays a functionally conserved role in cuticle formation in a diverse range of nematodes. Mol. Biochem. Parasitol. 169: 1-11.

Subhapradha, N., P. Ramasamy, V. Shanmugam, P. Madeswaran, A. Srinivasan, and A. Shanmugam. 2013. Physiochemical characterization of $\beta$-chitosan from Sepioteuthis lessoniana gladius. Food Chem. 141: 907-913.

Suzuki, M., and H. Nagasawa. 2013. Mollusk shell structures and their formation mechanism. Can. J. Zool. 91: 349-366.

Tan, Y. P., S. Hoon, P. A. Guerette, W. Wei, A. Ghadban, C. Hao, A. Miserez, and J. H. Waite. 2015. Infiltration of chitin by protein coacervates defines the squid beak mechanical gradient. Nat. Chem. Biol. 11: $488-495$.

Thompson, J. T., R. M. Shelton, and W. M. Kier. 2014. The lengthforce behavior and operating length range of squid muscle vary as a function of position in the mantle wall. J. Exp. Biol. 217: 2181-2192.

Thompson, J. T., S. M. Lavalva, and M. M. Loiacono. 2016. A multifunction muscle in squid. Biol. Bull. 231: 225-235.

Tjoelker, L. W., L. Gosting, S. Frey, C. L. Hunter, H. L. Trong, B. Steiner, H. Brammer, and P. W. Gray. 2000. Structural and functional definition of the human chitinase chitin-binding domain. $\underline{\text { J. Biol. }}$ Chem. 275: 514-520.

Vasiliou, V., D. C. Thompson, C. Smith, M. Fujita, and Y. Chen. 2013. Aldehyde dehydrogenases: from eye crystallins to metabolic disease and cancer stem cells. Chem.-Biol. Interact. 202: 2-10.

Vazquez, F., G. Hastings, M.-A. Ortega, T. F. Lane, S. Oikemus, M. Lombardo, and M. L. Iruela-Arispe. 1999. METH-1, a human ortholog of ADAMTS-1, and METH-2 are members of a new family of proteins with angio-inhibitory activity. J. Biol. Chem. 274: 23349-23357.

Vold, I. M. N., and B. E. Christensen. 2005. Periodate oxidation of chitosans with different chemical compositions. Carbohydr. Res. 340: 679-684.

Vournakis, J. N., M. Demcheva, A. B. Whitson, S. Finkielsztein, and R. J. Connolly. 2003. The RDH bandage: hemostasis and survival in a lethal aortotomy hemorrhage model. J. Surg. Res. 113: 1-5.

Weiner, S., and L. Hood. 1975. Soluble protein of the organic matrix of mollusk shells: a potential template for shell formation. Science 190: $987-989$.

Williams, L. W. 1909. The Anatomy of the Common Squid Loligo pealii, Lesueur. Brill, Leiden.

Winkler, D. D., and K. Luger. 2011. The histone chaperone FACT: structural insights and mechanisms for nucleosome reorganization. J. Biol. Chem. 286: 18369-18374.

Woodward, M. P., W. W. Young, Jr., and R. A. Bloodgood. 1985. Detection of monoclonal antibodies specific for carbohydrate epitopes using periodate oxidation. J. Immunol. Methods 78: 143-153.

Wright, P. A. 1995. Nitrogen excretion: three end products, many physiological roles. J. Exp. Biol. 198: 273-281.

Wu, S.-D., C.-S. Wu, and H.-C. Chen. 2003. Cuticle structure of squid Illex argentinus pen. Fish. Sci. 69: 849-855.

Yang, F.-C., R. D. Peters, H. Dies, and M. C. Rheinstadter. 2014. Hierarchical, self-similar structure in native squid pen. Soft Matter 10: $5541-5549$.

Young, R. E., M. Vecchione, and D. T. Donovan. 1998. The evolution of coleoid cephalopods and their present biodiversity and ecology. S. Afr. J. Mar. Sci. 20: 393-420.

Yu, R., W. Liu, D. Li, X. Zhao, G. Ding, M. Zhang, E. Ma, K. Y. Zhu, S. Li, B. Moussian, and J. Zhang. 2016. Helicoidal organization of chitin in the cuticle of the migratory locust requires the function of the chitin deacetylase2 enzyme (LmCDA2). J. Biol. Chem. 291: 24352-24363. 